\title{
Pulmonary function changes after nebulised and intravenous frusemide in ventilated premature infants
}

Vishwanath G Prabhu, Martin Keszler, Ramasubbareddy Dhanireddy

\begin{abstract}
Aims-To compare the effects of a single dose of frusemide administered either intravenously or by nebulisation on pulmonary mechanics in premature infants with evolving chronic lung disease.

Methods-The effect of frusemide on pulmonary mechanics was studied at a median postnatal age of 23 (range 14-52) days in 19 premature infants at 24 to 30 weeks gestational age, who had been dependent on mechanical ventilation since birth. Frusemide (1 $\mathrm{mg} / \mathrm{kg} / \mathrm{body}$ weight) was administered, in random order, intravenously and by nebulisation, on two separate occasions 24 hours apart. Pulmonary function studies were performed before and at 30, 60, and $120 \mathrm{~min}$ utes after administration of frusemide. Urine was collected for six hours immediately before and for six hours after administration of frusemide.

Results-Nebulised frusemide increased the tidal volume 31 (SE 11.5)\% and compliance 34 (SE 12)\% after two hours, whereas no change in either was noted for up to two hours after intravenous frusemide administration. Neither intravenous nor nebulised frusemide had any effect on airway resistance. Six hour urine output increased from a mean (SE) of $3.3(0.4)$ $\mathrm{ml} / \mathrm{kg} / \mathrm{hour}$ to $5.9(0.8) \mathrm{ml} / \mathrm{kg} / \mathrm{hour}$ following intravenous frusemide administration while nebulised frusemide had no effect on urine output. Urinary sodium, potassium, and chloride losses were also significantly higher after intravenous frusemide, whereas nebulised frusemide did not increase urinary electrolyte losses.

Conclusion-Single dose nebulised frusemide improves pulmonary function in premature infants with evolving chronic lung disease without adverse effects on fluid and electrolyte balance.

(Arch Dis Child 1997;77:F32-F35)
\end{abstract}

Keywords: inhaled frusemide; pulmonary mechanics; chronic lung disease of prematurity

Fluid overload with pulmonary edema has been implicated in the pathogenesis of chronic lung disease of prematurity (CLD). ${ }^{1}$ Spitzer et al showed that infants who failed to have a diuretic response within 48 hours of birth had chest radiographs consistent with CLD and prolonged oxygen requirements compared with infants who responded with diuresis. ${ }^{2}$
Several studies have demonstrated an improvement in pulmonary function with systemic diuretics in infants with CLD, and systemic administration of frusemide is widely used in the management of infants with CLD. ${ }^{3-7}$ However, this mode of administration is associated with fluid and electrolyte imbalance, ${ }^{4}$ especially in preterm infants. Frusemide can also be used as a new antiasthmatic drug when administered by inhalation. ${ }^{8}{ }^{9}$ Rastogi et al studied pulmonary mechanics in neonates with increasing dose of nebulized frusemide and demonstrated improvement in pulmonary mechanics with $1 \mathrm{mg} / \mathrm{kg} /$ body weight while a lower dose produced no improvement. ${ }^{10}$ However, that study did not include a control group which received systemic frusemide. We designed this study to test the hypothesis that a single dose of frusemide administered by nebulisation to preterm infants with evolving chronic lung disease will be as effective as a single dose of intravenous frusemide in improving pulmonary function, without causing fluid and electrolyte imbalance.

\section{Methods}

Newborn infants who were ventilated and oxygen dependent for 14 or more days since birth for primary lung disease were enrolled when the physician caring for the infant decided to initiate diuretic treatment with frusemide. Infants with major congenital anomalies were excluded. The study was approved by both the Food and Drug Administration and the Georgetown University Medical Center Institutional Review Board. Informed consent was obtained from the parents before enrolment. The first dose of frusemide was administered either intravenously or by inhalation in random order. An infant who received the first dose by the intravenous route received the second dose by inhalation and vice versa. The design of the study was randomised crossover with subjects acting as their own controls. Eleven infants were randomly assigned to intravenous frusemide first compared with eight infants who received nebulised frusemide first. The interval between the two doses was always 24 hours. Both intravenous and nebulised frusemide were administered at a dose of $1 \mathrm{mg}$ per kilogram of body weight. Aerosol solution of frusemide was prepared by diluting the intravenous preparation (frusemide injection, USP, $10 \mathrm{mg} / \mathrm{ml}$, Astra USA, Inc. Westborough, MA 01581) 15-30 times with $2 \mathrm{ml}$ of $0.9 \%$ sodium chloride, and was administered to the infant using the MiniHeart nebuliser (Vortran 


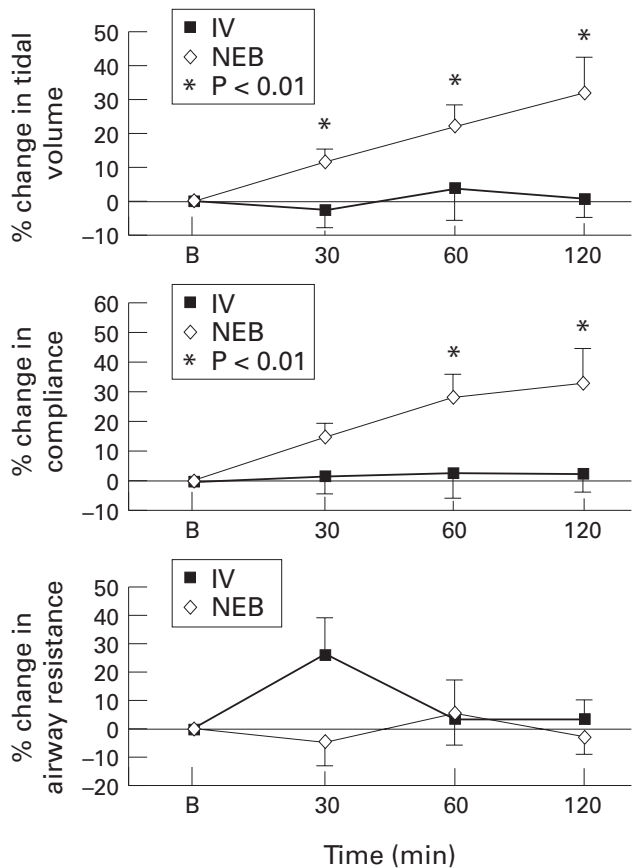

Figure 1 Per cent changes from baseline values in tidal volume, compliance, and airway resistance after intravenous and nebulised frusemide administration. Bold line represents intravenous, and shaded line, nebulised route. Data are mean (SE) $B=$ before frusemide administration.

Medical Technology, Inc, Sacramento, CA). The nebuliser was connected to the inspiratory limb of the ventilator circuit at a fixed length from the infant's lips and entire dose of frusemide was administered at a flow of 2 $1 /$ minute over 5 to 10 minutes. In infants who were receiving nebulised bronchodilator treatment (albuterol, terbutaline), the treatments were withheld for four hours before and during the two hours of the study. Infants who were receiving theophylline continued to have this treatment throughout the study, but no infant started to receive theophylline during the two day study period. No infant was given any other diuretics or glucocorticosteroids either before or during the study.

Pulmonary function tests were performed 10 minutes before and at 30,60, and 120 minutes after the administration of frusemide. The pulmonary function tests were done when the infants were calm and quiet, lying supine on a flat surface, neck in neutral position and chin in midline. No sedatives were administered to the infants during the study. Air flow was measured using a Hans Rudolph pneumotachometer (model 8411A, Hans Rudolph, Inc, Kansas City, MO) and a Validyne (model MP45, Validyne Engineering Co, Northridge, CA) differential pressure transducer placed in series with the endotracheal tube and the ventilator. The calibrated flow range for the pneumotachometer used in our study is 0 to $0.166 \mathrm{l} /$ second. The resistance to flow with this pneumotachometer is 2 litres/minute for a flow of 10 litres/minute and has a dead space of $1.3 \mathrm{ml}$. Infants were monitored continuously with a cardiorespiratory monitor and pulse oximetry. Pulmonary function tests at 30,60 , and 120 minutes were done at the same ventilator pres- sures, flow, and the inspiratory time as those found at 10 minutes before frusemide administration (at base line). We took care to ensure that the peak inspiratory pressure (PIP) and positive end expiratory pressure (PEEP) remained constant throughout the pulmonary function tests. The infants studied were ventilated using a Dragger Babylog 8000 ventilator which shows percentage of endotracheal air leak. Any air leak detected was rectified before the pulmonary function tests. All pulmonary function tests were measured using mechanical breaths with the ventilator rate of $60 /$ minute, inspiratory time of 0.3 seconds. All pulmonary function studies had a minimum of 10 mechanical breaths computed. Pulmonary mechanics were studied using a two factor least mean square analysis technique, as described by Bhutani et al. ${ }^{11}$

Urine was collected for six hours before and for six hours after the administration of frusemide by using clean nappies. Urine volume was measured by weighing the diapers and the urinary electrolyte concentrations were measured from the urine obtained from the nappies. ${ }^{12}$ No changes were made in fluid or electrolyte intake during the six hour period before and after each dose.

Analysis of variance for repeat measures and Fisher's PLSD post hoc test were used for comparison of pulmonary function tests and the paired $t$ test was used for comparison of urine values. A P value of less than 0.05 was considered to indicate significance. Data are expressed as mean and standard deviation (SD) or standard error of the mean (SE).

\section{Results}

Nineteen preterm infants (six female) with a mean (SD) gestational age of 26.2 (2.1) weeks (median 26; range 24-30 weeks) and a mean (SD) birth weight of 800 (170) g (median 790; range $670-1140 \mathrm{~g}$ ) were enrolled in the study. The mean (SD) postnatal age at the time of the study was 27 (11) days (median 23; range 14-52 days) and the weight was 910 (180) g (median 900; range 730-1280 g). The mean (SD) postconceptional age was 30 (2.4) weeks (median 30; range 27.5-35 weeks) at the time of the study. The infants enrolled were ventilated for respiratory distress syndrome and had been ventilator dependent for at least 14 days or more since birth.

The per cent changes from the baseline in expiratory tidal volume, total pulmonary compliance, and resistance are shown in fig 1. Baseline tidal volume, compliance, and pulmonary resistance values were comparable before intravenous and nebulised frusemide administration (table 1). Mean (SE) tidal volume increased 31(11.5)\% two hours after nebulised frusemide; intravenous frusemide had no effect on tidal volume (values are presented in table 1). Nebulised frusemide produced a 34 (SE 12) $\%$ increase in pulmonary compliance in two hours; no change in pulmonary compliance was noted after intravenous frusemide. Frusemide administration, either intravenously or by nebulisation, had no effect on airway resistance (table 1). 
Table 1 Effect of furosemide on pulmonary function in premature infants

\begin{tabular}{|c|c|c|c|c|c|c|}
\hline \multirow[b]{2}{*}{ Measurement } & \multirow{2}{*}{$\begin{array}{l}\text { Route of } \\
\text { administration }\end{array}$} & \multirow{2}{*}{$\begin{array}{l}\text { Before mean } \\
(S E)\end{array}$} & \multicolumn{4}{|c|}{ Minutes after mean (SE) } \\
\hline & & & 30 & 60 & 120 & $P$ value \\
\hline \multirow[t]{2}{*}{ Tidal volume $(\mathrm{ml} / \mathrm{kg})$} & Nebulised & $7.3(0.3)$ & $8.0 \quad(0.4)$ & $8.8 \quad(0.5)$ & $9.3 \quad(0.7)$ & 0.001 \\
\hline & Intravenous & $8.2(0.5)$ & $7.9 \quad(0.5)$ & $8.4 \quad(0.7)$ & $8.2(0.6)$ & 0.7 \\
\hline \multirow{2}{*}{ Compliance $\left(\mathrm{ml} / \mathrm{kg} / \mathrm{cmH}_{2} \mathrm{O}\right)$} & Nebulised & $0.58(0.03)$ & $0.65(0.03)$ & $0.73(0.04)$ & $0.76(0.06)$ & 0.002 \\
\hline & Intravenous & $0.66(0.05)$ & $0.65(0.05)$ & $0.67(0.07)$ & $0.68(0.07)$ & 0.96 \\
\hline \multirow[t]{2}{*}{ Resistance $\left(\mathrm{cmH}_{2} \mathrm{O} / 1 / \mathrm{sec}\right)$} & Nebulised & $(8.3)$ & $(8.3)$ & (12.5) & $(6.1)$ & 0.6 \\
\hline & Intravenous & $(7.0)$ & (13.3) & $(5.8)$ & $(11.2)$ & 0.15 \\
\hline
\end{tabular}

Table 2 Ventilator settings and transcutaneous $\mathrm{O}_{2}$ saturation data (values are mean (SE))

\begin{tabular}{|c|c|c|c|c|c|c|c|c|c|c|}
\hline \multirow[b]{3}{*}{ Ventilator settings } & \multicolumn{10}{|c|}{ Route of frusemide administration } \\
\hline & \multicolumn{5}{|c|}{ Intravenous } & \multicolumn{5}{|c|}{ Nebulised } \\
\hline & Befor & & After & & P value & Befor & & After & & $P$ value \\
\hline $\mathrm{FIO}_{2}$ & 0.37 & $7(0.03)$ & 0.37 & $(0.03)$ & 1.0 & 0.45 & $(0.03)$ & 0.3 & $(0.04)$ & 0.04 \\
\hline $\mathrm{PIP}\left(\mathrm{cm} \mathrm{H}_{2} \mathrm{O}\right)$ & 17.8 & $(0.62)$ & 17.8 & $(0.62)$ & 1.0 & 17.7 & $(0.58)$ & 17.7 & $(0.55)$ & 0.67 \\
\hline PEEP $\left(\mathrm{cm} \mathrm{H}_{2} \mathrm{O}\right)$ & 5.0 & $(0.17)$ & 5.1 & $(0.18)$ & 0.33 & 5.0 & $(0.17)$ & 5.0 & $(0.17)$ & 1.0 \\
\hline Rate (breaths $/ \mathrm{min}$ ) & 29 & (4) & 29 & (4) & 0.59 & 26 & (3) & 27 & (3) & 0.87 \\
\hline Transcutaneous $\mathrm{O}_{2}$ saturation (\%) & 95 & $(0.79)$ & 95 & $(0.65)$ & 0.8 & 94 & $(0.66)$ & 96 & $(0.66)$ & 0.21 \\
\hline
\end{tabular}

* Values are 2 hours after the administration of frusemide.

Table 3 Effect of frusemide on 6 hour urine output and urinary electrolyte excretion in premature infants (values are mean (SE))

\begin{tabular}{|c|c|c|c|c|c|c|}
\hline \multirow[b]{3}{*}{ Urine measurement } & \multicolumn{6}{|c|}{ Route of frusemide administration } \\
\hline & \multicolumn{3}{|c|}{ Intravenous } & \multicolumn{3}{|l|}{ Nebulised } \\
\hline & Before & After & Pvalue & Before & After & P value \\
\hline Output (ml/kg/hour) & $3.3(0.4)$ & $5.9(0.8)$ & 0.006 & $3.0(0.5)$ & $2.9(0.4)$ & 0.84 \\
\hline Sodium (mEq/kg/hour) & $0.8(0.1)$ & $2.7(0.6)$ & 0.004 & $0.8(0.1)$ & $0.6(0.1)$ & 0.03 \\
\hline Potassium (mEq/kg/hour) & $0.3(0.1)$ & $0.5(0.1)$ & 0.01 & $0.4(0.1)$ & $0.4(0.1)$ & 0.91 \\
\hline Chloride ( $\mathrm{mEq} / \mathrm{kg} /$ hour $)$ & $0.9(0.1)$ & $2.5(0.5)$ & 0.005 & $0.9(0.2)$ & $0.7(0.1)$ & 0.03 \\
\hline
\end{tabular}

There was no correlation between the postnatal age at the time of the study and the tidal volume or compliance improvement after nebulised frusemide administration. The effects of nebulised frusemide on tidal volume and compliance were also independent of days on mechanical ventilation and the postconceptional age (data not shown). No additive effects after nebulised frusemide administration were detected in infants who received intravenous frusemide first, and vice versa. Ventilator settings, $\mathrm{FIO}_{2}$, and transcutaneous oxygen saturation data are presented in table 2. $\mathrm{FIO}_{2}$ requirement decreased from $45 \%$ before to $39 \%$ two hours after the administration of nebulised frusemide $(\mathrm{P}=0.04)$. There was no change in the $\mathrm{FIO}_{2}$ requirement before and two hours after intravenous frusemide administration. Ventilator pressure, ventilator rate, and transcutaneous $\mathrm{O}_{2}$ saturation values showed no difference two hours after compared with before frusemide administration using either route. No episodes of clinically important transcutaneous oxygen desaturation $(<85 \%)$, increased supplemental oxygen requirement, or tachycardia were noted during the study.

Urinary output and electrolyte losses before and after frusemide administration are presented in table 3. Intravenous frusemide produced significant diuresis with increased electrolyte losses in the urine. Nebulised frusemide had no effect on urine output. There was a small but significant decrease in sodium and chloride excretion after nebulised frusemide administration.

\section{Discussion}

Infants with CLD have clinical, radiographic, and histological evidence of both interstitial and peribronchiolar pulmonary oedema. ${ }^{13}$ Systemic frusemide is widely used in the management of evolving CLD. ${ }^{14}$ Although diuretic treatment increases urine output, even short term improvement in lung function has not been shown to be related to the magnitude of the diuretic response. ${ }^{15}$ Improvement in lung function in anuric infants after systemic frusemide administration indicates that the pulmonary effects of frusemide are independent of its diuretic effect. ${ }^{14}$ Improvement in oxygenation and reduction in total lung liquid with systemic frusemide in dogs who have had their kidneys removed were comparable with those found in normal dogs. ${ }^{16}$ The mechanism of action by which frusemide and other drugs with diuretic properties improve lung mechanics is not clear. In adults nebulised frusemide is now regarded as a potential antiasthmatic drug. ${ }^{8} 9$ It has been found to be a potent inhibitor of bronchoconstriction induced by agents such as cold air hyperventilation, sodium metabisulphite, and adenosine-5monophosphate and methacholine. ${ }^{17-20}$

Proposed mechanisms of action of nebulised frusemide on airways are: inhibition of $\mathrm{Na}$ / $\mathrm{K} / \mathrm{Cl}$ co-transport system in airway epithelium, thus maintaining the airway osmolarity. ${ }^{821}$ increase in the airway epithelial derived $\mathrm{PGE}_{2}$ and pulmonary endothelial derived $\mathrm{PGI}_{2}^{22}$ reduction in the intracellular sodium and consequently intracellular calcium, thus inducing 
airway smooth muscle relaxation. ${ }^{8}$ Inhibition of the release of mediators like leukotriene $\mathrm{C} 4$, histamine, and neutrophil chemotactic factors by the inflammatory cells. ${ }^{23}{ }^{24}$ In this study improvement in tidal volume and pulmonary compliance was apparent within 30 minutes and persisted for up to the study period of two hours after the administration of frusemide by nebulisation. The effects of nebulised saline alone on lung mechanics cannot be determined from this study, but a previous study showed that frusemide nebulised at doses of $0.1,0.25$, and $0.5 \mathrm{mg} / \mathrm{kg}$ body weight diluted in $2 \mathrm{ml}$ of $0.9 \%$ saline did not change the pulmonary mechanics in preterm infants with CLD. ${ }^{10}$ The apparent lack of response to intravenous frusemide is probably due to the use of a single dose. Systemic frusemide has to be administered for days before any major improvement in pulmonary mechanics is seen..$^{5-7}$ The faster and effective changes noticed with nebulised frusemide are probably due to its direct effect on lungs and airways. In our study we did not measure the pulmonary mechanics beyond two hours. The beneficial pulmonary effect with a single dose of nebulised frusemide was not associated with fluid and electrolyte imbalance.

Our study has shown that the pulmonary beneficial effects of nebulised frusemide are independent of its diuretic action. Rastogi et al demonstrated a measurable effect of nebulised frusemide on airway resistance in addition to its effect on tidal volume and pulmonary compliance. ${ }^{10}$ We observed improvement in tidal volume and compliance without a decrease in airway resistance. The reasons for this discrepancy are not clear, as the study population and the methods of measurements were similar. We are unable to explain the small but significant decrease in the excretion of sodium and chloride in the urine following the administration of nebulised frusemide. The clinical importance of this finding is unclear.

We conclude that a single dose of nebulised frusemide improved tidal volume and compliance compared with a single dose of intravenous frusemide for up to the study period of two hours without producing fluid and electrolyte imbalance in mechanically ventilated preterm infants. Further studies are needed to determine optimal dose, frequency of administration, and long term risks and benefits of nebulised frusemide on developing lung and its airway if it it is to be used for prolonged periods of time.
1 Brown ER, Stark A, Sosenko I, Lawson EL, Avery ME. Bronchopulmonary dysplasia- possible relationship to pulmonary edema. F Pediatr 1978; 92:982-4.

2 Spitzer AR, Fox WW, Delivoria-Papadopoulous M. Maximum diuresis- a factor in predicting recovery from respiratory distress syndrome and development of bronchopulmonary dysplasia. F Pediatr 1981; 98:476-9.

3 Blanchard PW, Brown TM, Coates AL. Pharmacotherapy in bronchop

4 Patel H, Yeh TF, Jain R, Pildes R. Pulmonary and renal responses to furosemide in infants with stage 3-4 BPD. Am f Dis Child 1985;139:917-9.

5 Kao L, Warburton D, Cheng M, Cedeno C, Platzker A, Keens T. Effect of oral diuretics on pulmonary mechanics in infants with chronic BPD: results of double blind cross in infants with chronic BPD: results of double
over sequential trial. Pediatrics 1984;74:37-44.

6 McCann EM, Deming DD, Brady JP. Lasix improves lung function in infants with chronic lung disease. Clin Res 1983;31:141A

7 Najak KZ, Harris EM, Lazzara A, Pruitt AW. Pulmonary effects of furosemide in premature infants with lung disease. Pediatr Res 1981;15:783-7.

8 Anonymous. Inhaled furosemide and asthma [editorial]. Lancet 1990;21:944-6.

9 Bianco S, Pieroni MG, Refini RM, Robuschi M, Vaghi A, Sestini P. Inhaled loop diuretics as potential new anti-asthmatic drugs. Eur Respir f 1993;6:130-4.

10 Rastogi A, Luayon M, Ajayi OA, Pildes RS. Nebulized furosemide in infants with bronchopulmonary dysplasia. $\mathcal{F}$ Pediatr 1994;125:976-9.

11 Bhutani VK, Siviri EM, Abbasi S, Shaffer TH. Evaluation of neonatal pulmonary mechanics and energies; A two factor least mean square analysis. Pediatr Pulmonol 1988;4:150-8.

12 Beeram M, Dhanireddy R. Urinalysis: Direct versus diaper collection. Clin Pediatr 1991;30:278-280.

13 Bland RD. Edema formation in the newborn lung. Clin Perinatol 1982;9:593-611.

14 Rush MG and Hazinski TA. Current therapy of bronchopulmonary dysplasia. Clin Perinatol 1992;19:563-90.

15 Rush MG, Engelhardt B and Parker RA. Double blind, placebo-controlled trial of alternate day furosemide therapy in infants with chronic bronchopulmonary dysplasia. $\mathcal{F}$ Pediatr 1990;117:112-18.

16 Ali J, Chernicki W and Wood LD. Effect of furosemide in canine low pressure pulmonary edema. F Clin Invest 1979;64:1494-504

17 Nichol GM, Alton EW, Nix A, Geddes DM, Chung KF, Barnes PJ. Effect of inhaled furosemide on metabisulfiteand methacholine-induced bronchoconstriction and nasal potential difference in asthmatic subjects. Am Rev Respir Dis 1990;142:576-80.

18 O'Connor BJ, Chung KF, Chen-Worsdell YM, Fuller RW, Barnes PJ. Effect of inhaled furosemide and bumetanide on adenosine 5'-monophosphate- and sodium metabisulfite-induced bronchoconstriction in asthmatic subjects. Am Rev Respir Dis 1991;143:1329-33.

19 O’Donnell WJ, Rosenberg M, Niven RW, Drazen JM, Israel E. Acetazolamide and furosemide attenuate asthma induced by hyperventilation of cold, dry air. Am Rev Respir Dis 1992;146:1518-23.

20 Foresi A, Pelucchi A, Mastropasqua B, Cavigioli G, Carlesi RM, Marazzini L. Effect of inhaled furosemide and torasemide on bronchial response to ultrasonically nebulized distilled water in asthmatic subjects. Am Rev Respir Dis 1992;146:364-8.

21 Polosa R, Lau LCK, Holgate ST. Inhibition of adenosine 5'-monophosphate and methacholine induced bronchoconstriction in asthma by inhaled furosemide. Eur Respir $\mathcal{F}$ 1990;3:665-72.

22 Pavord ID, Wisniewski A, Tattersfield AE. Inhaled frusemide and exercise induced asthma: evidence of a role for inhibitory prostanoids. Thorax 1992;47:797-800.

23 Anderson SD, Temple DM, Wei HE. Inhibition of furosemide of inflammatory mediators from lung fragments ide of inflammatory mediators from
(letter). $N$ Engl $\mathcal{M}$ Med 1991;324:131.

24 Mosacato G, Dellabianca A, Falagiani P, Mistrello G, Rampulla C. Inhaled furosemide prevents both the bronchoconstriction and the increase in neutrophil chemotactic activity induced by ultrasonic 'fog' of distilled water in asthmatics. Am Rev Respir Dis 1991;143:561-6. 